\title{
Effects of Three Phase AC / DC Converter Drive on the Torque-Speed Characteristic of DC Motor
}

\author{
Mohamed. A. Enany \\ Electrical Power \& Machines Department, Faculty of Engineering, Zagazig University. \\ Zagazig University, Zagazig, Egypt.
}

\begin{abstract}
This paper presents the three phase AC/DC converter drive effects on the linearity of the Torque-speed characteristics. A MATLAB/Simulink realization of the three phase AC/DC converter drive is described. The DC motor speed control is achieved by controlling the voltage applied to the armature circuit using three phase AC/DC converter drive. A comparison between the application of three phase semi converter and three phase full converter is presented. At different values of firing angle, the Torque-speed characteristics are obtained to demonstrate three phase AC/DC converter drive effects on the linearity of the characteristic.
\end{abstract}

\section{Keywords}

MATLAB/Simulink, DC motor drive, and Three phase $\mathrm{AC} / \mathrm{DC}$ converter drive.

\section{INTRODUCTION}

MATLAB / Simulink is one of the most popular software packages, which has been used as a computer modeling to support and enhance electric machinery courses [1-3]. Field control, armature voltage control, and armature resistance control methods are the main methods DC motors speed [4]. The armature voltage control method is, the commonly method used in practice to control the DC motor speed. A power electronic converter controllable rectifier or PWM chopper will supply the DC motors in this method. Therefore, nonlinear torque-speed characteristics would be observed in the DC motor drive performance [5-7]. This paper presents a Simulation model of a DC motor speed control method in which a three phase AC/DC semi and full converters drive are used to control the voltage applied to the armature. Torque speed characteristics are obtained for different values of firing angle to demonstrate its effect on the linearity of the characteristic.

\section{TORQUE-SPEED CHARACTERISTIC AND SPEED CONTROL METHOD ANALYSIS}

To analyze the torque speed characteristics using the equivalent circuit, the dynamic and steady-state models are needed. The schematic representation of the model of a separately excited DC motor is shown in Fig.1. In this figure, $V_{t}$ is the terminal voltage applied to the motor, $R_{a}$ and $L_{a}$ are the resistance, and inductance of the armature circuit; respectively; $R_{f}$ and $L_{f}$ are the resistance, and inductance of the field circuit, respectively; $E_{a}$ is the generated speed voltage; $\omega_{m}$ is the angular speed of the motor; $T_{e}$ and $T_{l}$ are the electromagnetic torque developed by the motor and the mechanical load torque opposing direction.

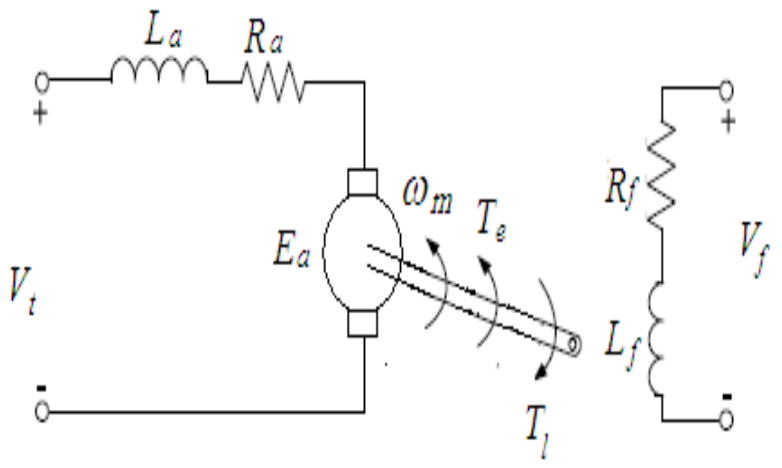

Fig. 1 Equivalent circuit of separately excited DC motor.

The torque-speed characteristic of a separately excited DC motor under the steady-state conditions is described by the following equation [6]:

$$
\omega_{m}=\frac{V_{t}}{K \phi}-\frac{R_{a}}{(K \phi)^{2}} T_{e}
$$

Where $K$ is the design constant depending on the construction of the motor.

Equation (1) indicates the speed of a DC motor can be varied by controlling the field flux, the armature resistance or the terminal voltage applied to the armature. The three most common speed control methods are field resistance control, armature voltage control and armature resistance control methods. Since this paper presents Simulink model of speed control method by controlling the terminal voltage applied to the armature using a three phase AC/DC converter drive, only the armature voltage control method is briefly described in this section. In the armature voltage control method, the voltage applied to the armature circuit, $V_{t}$ is varied without changing the voltage applied to the field-circuit of the motor. As equation (1) indicates, the torque-speed characteristic is represented by a straight line with a negative slope when the DC motor is driven from an ideal DC source. In order for the speed of the motor vary linearly with torque, the terminal voltage $V_{t}$ and the flux $\varphi$ must remain constant as the load changes. Typically a rectifier is required to provide the controlled armature voltage for the motor whose speed is to be controlled. Observe that the no-load speed of the motor 
increases while the slope of the curve remains unchanged since the flux is kept constant in this method. By the armature voltage control method, it is possible to control the speed of the motor for speeds below base speed but not for speeds above base speed. In order to achieve a speed faster than the base speed, an excessive armature voltage is required, which in the simulation model. Fig. 2 shows the Simulink realization of the semi converter drive. The armature circuit is supplied from a three phase semi converter in which a thyristor is used as an electronic switch and a freewheeling diode is used to solve the stored inductive energy problem in the circuit. The field circuit is separately excited from an ideal DC voltage source. A DC motor block of SimPowerSystems toolbox is

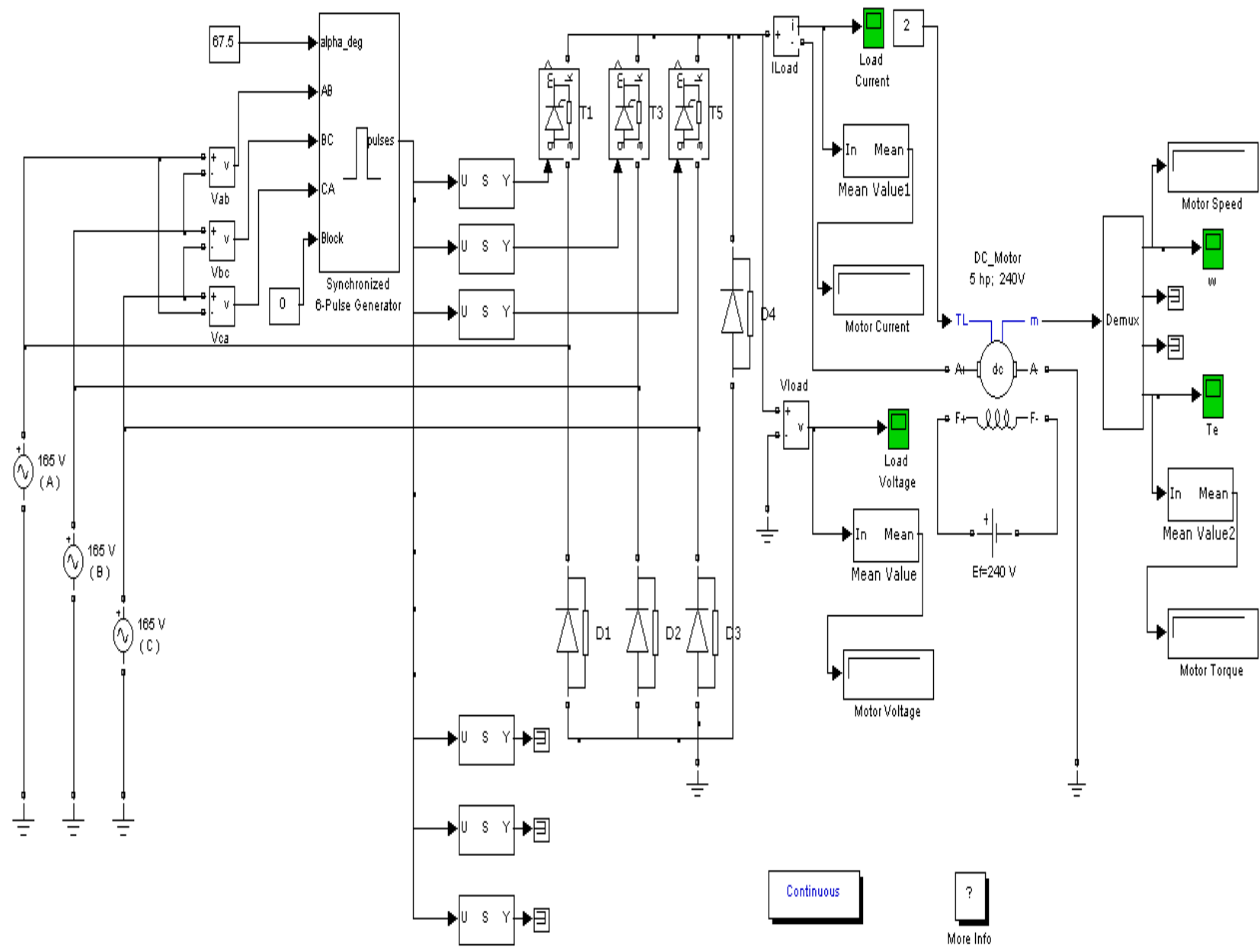

possibly damages the armature circuit.

\section{SIMULINK MODEL OF ARMATURE VOLTAGE SPEED CONTROL}

In this section, MATLAB/Simulink model of DC motor driven from single phase AC/DC semi and full converters are presented and the performance of the DC motor drive is analyzed. A 5-HP DC motor of $240-\mathrm{V}$ rating $1220 \mathrm{rpm}$ is used used.

Where, Fig. 3 shows the Simulink realization of the full converter drive. The armature circuit is supplied from a three phase full converter in which a thyristor is used as an electronic switch and no freewheeling diode is used. The field circuit is separately excited from an ideal DC voltage source. A DC motor block of SimPowerSystems toolbox is used. 


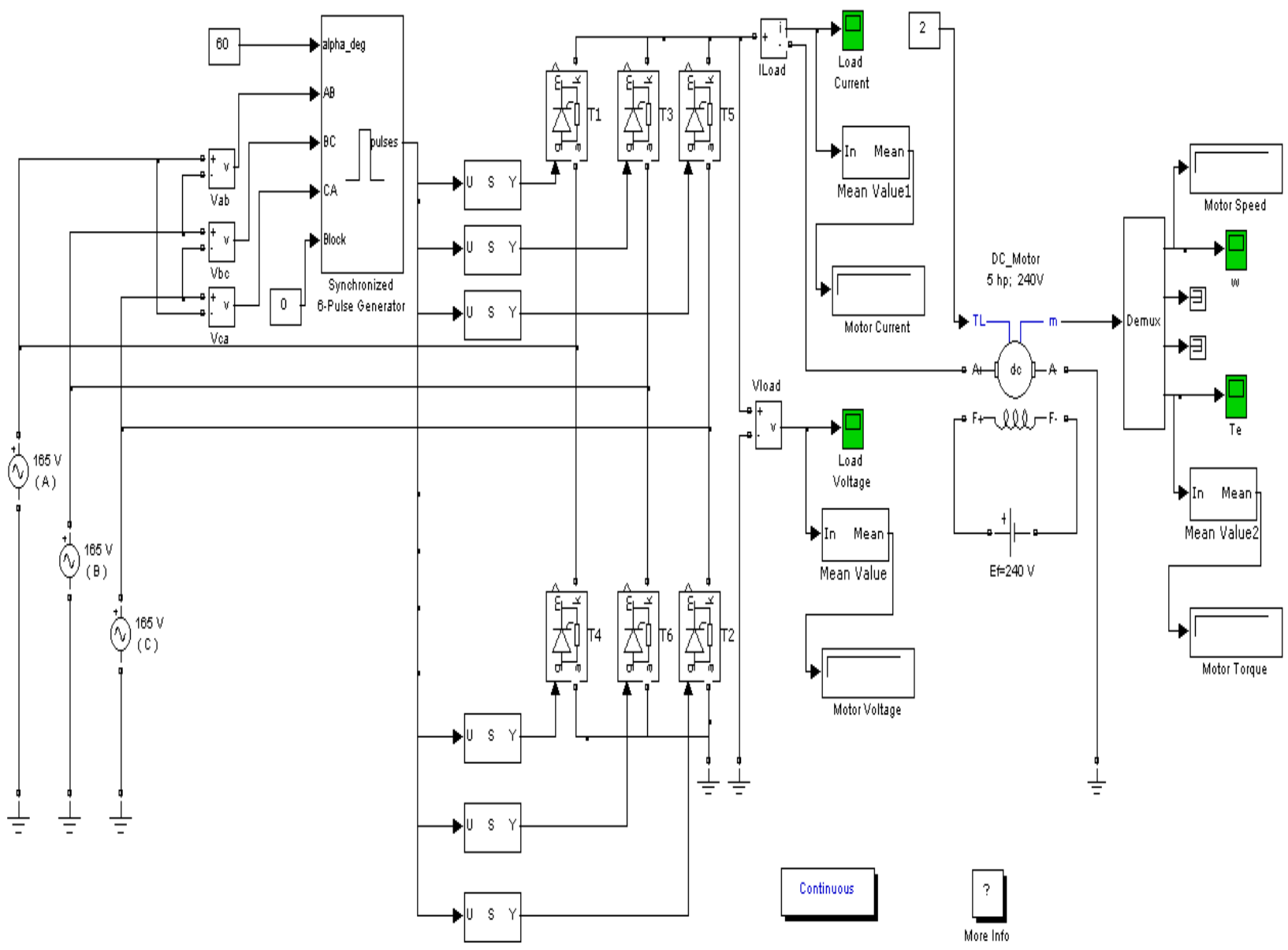

Fig. 3 Simulink realization of armature voltage speed control method using a three phase full converter

\section{SIMULATION RESULTS}

\subsection{Three Phase Semi converter Drive}

In order to investigate the effect of armature voltage on the torque-speed characteristic, Four different armature voltages with average values $V_{t}=240 \mathrm{~V}, 200 \mathrm{~V}, 160 \mathrm{~V}$ and $120 \mathrm{~V}$ are applied while the voltage applied to the field circuit is kept constant at its nominal value $240 \mathrm{~V}$. An AC supply with constant value is applied to the input of three phase semi converter. The average value of the converter output is changed by changing the firing angle $(\alpha)$. A pulse generator is used to change the firing angle. The following firing angles are used to obtain $120,160,200$ and $240 \mathrm{~V}$ average output voltages applied to the armature: $\alpha=89^{\circ}, 70^{\circ}, 47.5^{\circ}$ and $0^{\circ}$. The torque-speed characteristics are obtained for these armature voltages.

Fig. 4 shows the torque-speed curves for a single phase semi converter drive.

It is clear that torque-speed curves contain both linear and non-linear regions. The linear region of operation for $240 \mathrm{~V}$ approximately starts at $T_{L}=10 \mathrm{~N} . \mathrm{m}$. But for $200 \mathrm{~V}, 160 \mathrm{~V}$ and $120 \mathrm{~V}$ start at $T_{L}=30 \mathrm{~N} . \mathrm{m}$.

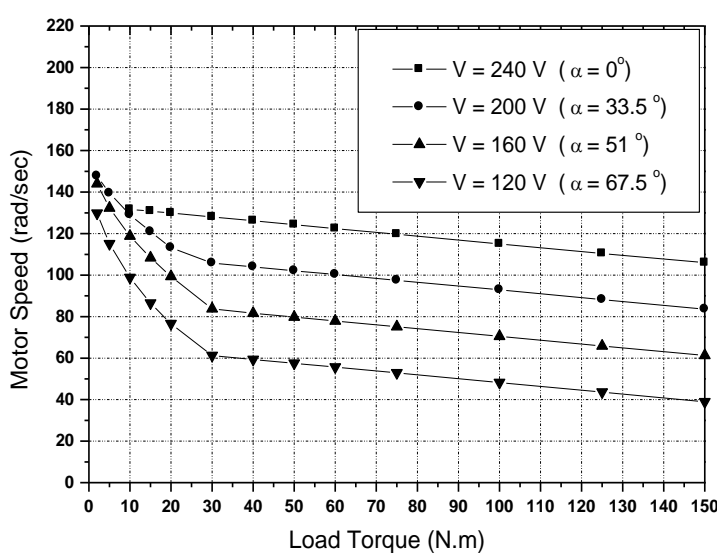

Fig. 4 Torque-speed characteristics for a three phase semi converter drive.

The discontinuous armature current results in a highly nonlinear torque-speed characteristic. Fig. 5 and Fig. 6 show the armature voltage and current obtained at $20 \mathrm{Nm}$ (in the nonlinear region) and $100 \mathrm{Nm}$ (in the linear region) for average value of $160 \mathrm{~V}$. These figures clearly illustrate the discontinuous and continuous operation of the three phase semi converter drive in non-linear and linear regions, respectively. 


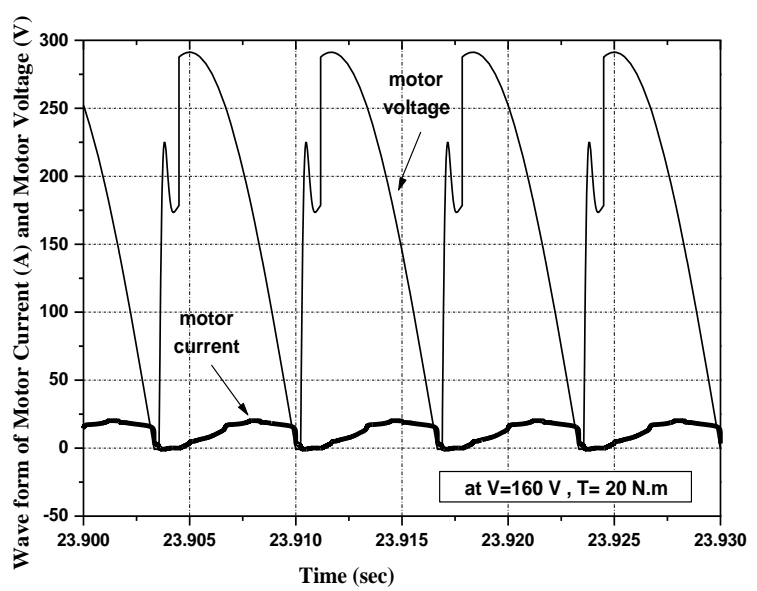

Fig. 5. Armature current and voltage for $160 \mathrm{~V}$ at $20 \mathrm{Nm}$ for three phase semi converter drive.

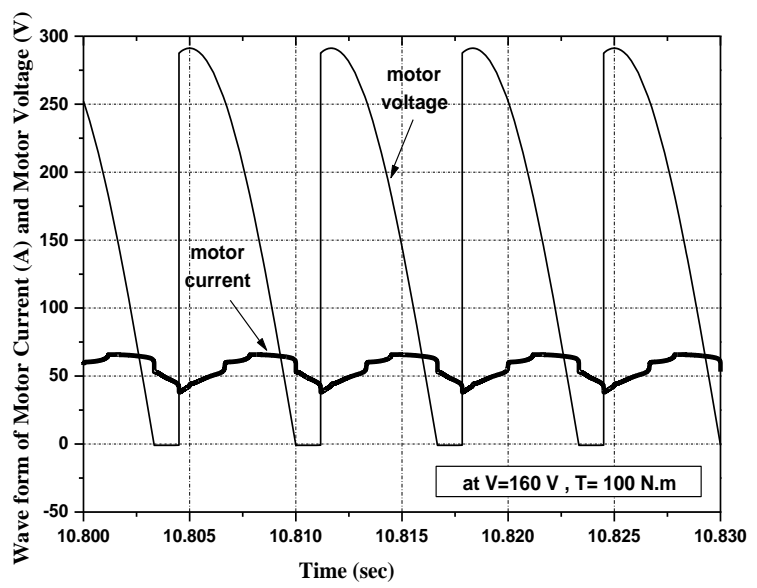

Fig. 6. Armature current and voltage for $160 \mathrm{~V}$ at $100 \mathrm{Nm}$ for three phase semi converter drive.

\subsection{Three Phase Full converter Drive}

To investigate the effect of three phase full converter on the torque-speed characteristic, the average value of the converter output is changed by changing the firing angle $(\alpha)$. A pulse generator is used to change the firing angle. The following firing angles are used to obtain 120, 160, 200 and $240 \mathrm{~V}$ average output voltages applied to the armature: $\alpha=60^{\circ}$, $48^{\circ}, 32.5^{\circ}$ and $0^{\circ}$. The torque-speed characteristics are obtained for these armature voltages.

Fig.7 shows the torque-speed curves for a single phase full converter drive.

It is clear that torque-speed curves contain both linear and non-linear regions. The linear region of operation for $240 \mathrm{~V}$ approximately starts at $T_{L}=10$ N.m. But for $200 \mathrm{~V}$ approximately starts at $T_{L}=30 \mathrm{~N}$.m. While for $160 \mathrm{~V}$ starts at $T_{L}=40$ N.m. Finally for $120 \mathrm{~V}$ approximately starts at $T_{L}=50 \mathrm{~N} . \mathrm{m}$.

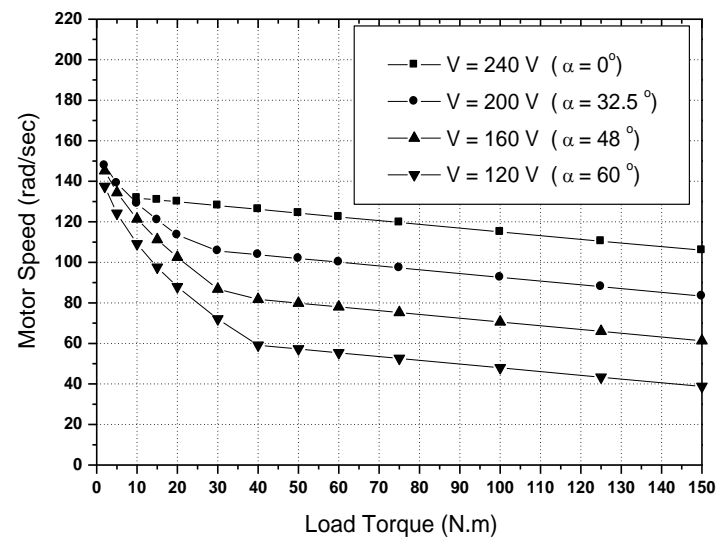

Fig. 7 Torque-speed characteristics for a three phase full converter drive.

The discontinuous armature current results in a highly nonlinear torque-speed characteristic. Fig. 8 and Fig. 9 show the armature voltage and current obtained at $20 \mathrm{Nm}$ (in the non-linear region) and $100 \mathrm{Nm}$ (in the linear region) for average value of $160 \mathrm{~V}$.

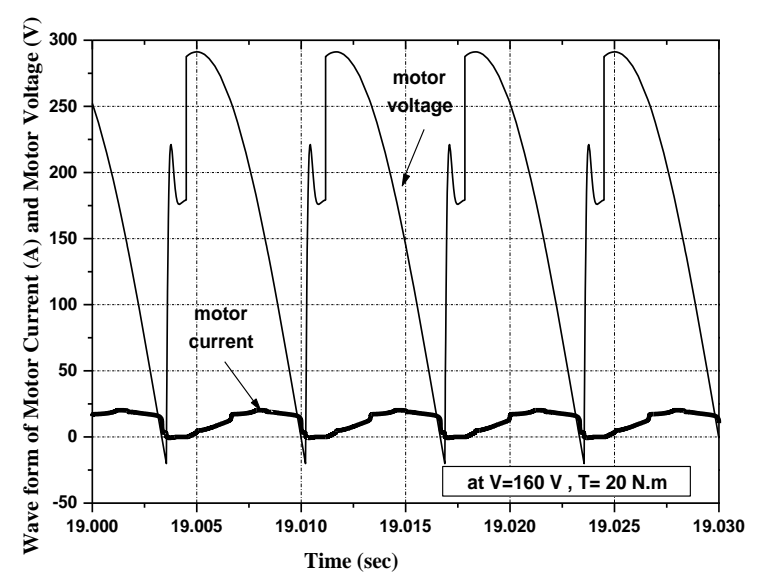

Fig. 8. Armature current and voltage for $160 \mathrm{~V}$ at $20 \mathrm{Nm}$ for three phase full converter drive.

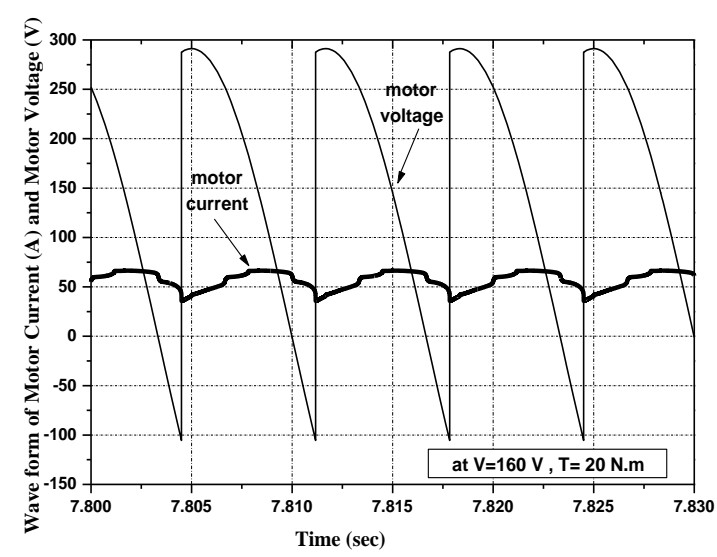

Fig. 9. Armature current and voltage for $160 \mathrm{~V}$ at $100 \mathrm{Nm}$ for three phase full converter drive. 
These figures clearly illustrate the discontinuous and continuous operation of the three phase full converter drive in non-linear and linear regions, respectively.

\section{CONCLUSION}

It is clearly seen that for all voltage values linear region of operation extends when three phase semi converter is used. As shown in Fig.10. For example, the region between 0 and 40 $\mathrm{Nm}$ was nonlinear for $120 \mathrm{~V}$ armature voltage for full converter drive. For semi converter drive the size of nonlinear region is shrunk to the region between 0 and $30 \mathrm{Nm}$. This is because of the fact that armature current becomes continuous and smoother for semi converter drive.

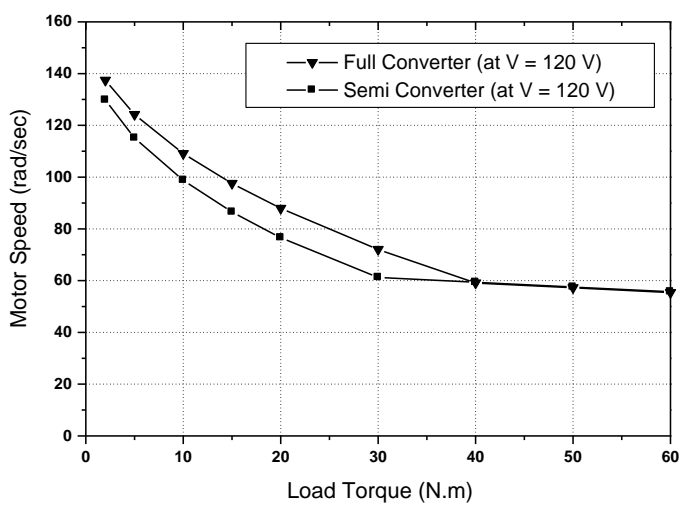

Fig. 10 Torque-speed characteristics for a three phase full converter drive and a semi converter for the same output voltage.

A Simulink model of DC motor speed control method which is realized using a three phase AC/DC converter is presented. Torque speed curves for two types of three phase AC/DC converter (full and semi converter) are obtained for a widerange of loading conditions. It is shown that torque-speed curves become nonlinear due to the discontinuity in armature current. Moreover, linearity of curves could be improved by using semi converter drive.

\section{APPENDIX}

The parameters of DC motor used in simulation are:

Rated output power $(\mathrm{P})=5 \mathrm{HP}$

Armature rated voltage $(\mathrm{V})=240 \mathrm{~V}$

Armature resistance $\left(\mathrm{R}_{\mathrm{a}}\right)=0.6 \Omega$

Armature inductance $\left(\mathrm{L}_{\mathrm{a}}\right)=0.012 \mathrm{H}$

Field resistance $\left(\mathrm{R}_{\mathrm{f}}\right)=240 \Omega$

Field inductance $\left(\mathrm{L}_{\mathrm{f}}\right)=120 \mathrm{H}$

Rated speed $(\mathrm{N})=1220 \mathrm{rpm}$

\section{REFERENCES}

[1] SIMULINK: Model-Based and System-Based Design, Using Simulink. . Natick, MA: MathWorks Inc., 2001.

[2] S. Li and R. Challoo, "Restructuring an electric machinery coursewith an integrative approach and computer-assisted teaching methodology," IEEE Transactions on Education., vol. 49, pp. 16- 28, Feb. 2006.

[3] W. M. Daniels and A. R. Shaffer, "Re-inventing the electrical machines curriculum," IEEE Transactions on Education, vol. 41, pp. 92-100, May 1998.

[4] S. J. Chapman, Electric Machinery Fundamentals. New York: WCB/McGraw-Hill, 1998.

[5] D. A. Staton, M. I. McGilp and T. J. E. Miller, "DC machine teaching experiment," in Proceedings of the European Power Electronics Association EPE, Brighton, 1993, pp. 35-40.

[6] A. Gelen and S. Ayasun, "Effects of PWM chopper drive on the torque-speed characteristic of DC motor " $43^{\text {rd }}$ International Universities Power Engineering Conference, 2008. UPEC 2008.

[7] M. Enany, "Effects of single phase AC/DC converter drive on the torque-speed characteristic of DC motor "in Proceedings of the 14th International Middle East Power Systems Conference (MEPCON'10), Cairo University, Egypt, December 19-21, 2010, pp. 782-785. Paper ID 284

\section{BIBLIOGRAPHY}

Mohamed A. Enany received his BS, MS and $\mathrm{PhD}$ from Faculty of Engineering, Zagazig University, Egypt, in 2000, 2005 and 2009, respectively, all in Electrical Power and Machines Engineering. He is currently an Assistant professor at the Electrical Power \& Machines Engineering Department, Faculty of Engineering, Zagazig University, zagazig , Egypt. 